\title{
Correction to: Identification of prognostic factors and construction of a nomogram for patients with relapse/refractory adult-onset Still's disease
}

\author{
Ruxue Yin ${ }^{1}$ - Gangjian Wang ${ }^{2}$ - Xiaopei Yang ${ }^{1}$ - Lei Zhang ${ }^{1}$ - Shuolin Wang ${ }^{1}$ - Tianfang Li ${ }^{1}$. Shengyun Liu ${ }^{1}$ (I)
}

Published online: 28 July 2021

(c) International League of Associations for Rheumatology (ILAR) 2021

\section{Correction to: Clinical Rheumatology}

https://doi.org/10.1007/s10067-021-05722-7

In the original published version of this article, the figures were not presented during production. These are now presented correctly.

The original article has been corrected.

Publisher's note Springer Nature remains neutral with regard to jurisdictional claims in published maps and institutional affiliations.

The original article can be found online at https://doi.org/10.1007/ s10067-021-05722-7.

Shengyun Liu

z18339909891@163.com

1 Department of Rheumatology, The First Affiliated Hospital of Zhengzhou University, No. 1 Jianshe East Road, Zhengzhou 450052, China

2 Department of Oncology, The First Affiliated Hospital of Zhengzhou University, No. 1 Jianshe East Road, Zhengzhou 450052, China 